\title{
Stress corrosion cracking at low loads: Surface slip and crystallographic analysis
}

Longkui Zhu ${ }^{\text {a,b }}$, Yu Yan ${ }^{\text {a }}$, Jinxu Li ${ }^{\text {a }}$, Lijie Qiao ${ }^{{ }^{*}}$, Zhengcao Li ${ }^{b}$, Alex A. Volinsky ${ }^{{ }^{*}}$

${ }^{\text {a }}$ Corrosion and Protection Center, Key Laboratory for Environmental Fracture

(MOE), University of Science and Technology Beijing, Beijing 100083, People's

Republic of China

${ }^{\mathrm{b}}$ Key Laboratory of Advanced Materials, School of Materials Science and

Engineering, Tsinghua University, Beijing 100084, People's Republic of China

${ }^{\mathrm{c}}$ Department of Mechanical Engineering, University of South Florida, Tampa, Florida

$$
\text { 33620, USA }
$$

\section{Abstract}

Stress corrosion cracking (SCC) of 316L single crystal was studied by scanning electron microscopy and electron backscatter diffraction. SCC could initiate and propagate without surface slip at the normal stress of $20 \mathrm{MPa}$. The cracks grew on the $\{100\}$ planes. Many microvoids appeared at the slip bands and microsteps were present on the fracture surfaces. Consequently, the synergistic effects of microcleavage and local dissolution induced SCC advance on $\{100\}$ crystal planes. Microshear was an additional SCC microscopic mechanism at high stress levels.

Keywords: A: Stainless steel; B: SEM; B: Modelling studies; C: Stress corrosion; C: Anodic dissolution; C: Effects of strains.

* Corresponding authors. Email: lqiao@ustb.edu.cn (L.J. Qiao); Phone: +86 106233 4499; Fax: +86 106233 2345; Email: volinsky@usf.edu (A.A. Volinsky), Phone: (813) 974-5658; Fax: (813) 974-3539.

(C) 2015. This manuscript version is made available under the Elsevier user license http://www.elsevier.com/open-access/userlicense/1.0/ 


\section{Introduction}

Stress corrosion cracking (SCC) experiments conducted during the last few decades show that environmental fracture in ductile face centered cubic (FCC) materials is the consequence of localized interactions between corrosion and dislocations [1-5]. Namely, local dissolution induces new stress concentrations, favoring the emission of dislocations and the formation of slip steps $[3,6]$. On the other hand, dislocations move to surfaces or slip steps and disrupt surface protective films. Then dislocations emerge on the surface and freshly exposed metal is chemically attacked [2, 7-14]. However, a novel SCC phenomenon has been observed where SCC cracks initiated and grew without any surface slip bands under low loads [15-17]. It is considered that dislocation pile-ups play an important role in the SCC process, and the emergence of slip bands is just an accompanying result at high stress levels, not contributing directly to SCC [15]. As proposed by the corrosion-enhanced plasticity model (CEPM), the increasing localized stresses by dislocation pile-ups and the decreasing critical stress intensity factor, $K_{\mathrm{ISCC}}$ due to hydrogen, jointly lead to the initiation of microcracks ahead of the main crack tip [5-6, 18-21]. Therefore, it is likely to form an SCC crack via dislocation pile-ups. Another explanation for SCC without any slip bands is that brittle films formed by anodic dissolution can break at small strains before the base metal yielding [12]. Indeed, the comparison of elastic behavior of the aircraft structural A97075 Al-alloy and bulk $\mathrm{Al}_{2} \mathrm{O}_{3}$ oxide demonstrates that the fracture strain of aluminum oxide, $\varepsilon_{\mathrm{f}}=0.0007$, is 
much less than the elastic limit of the aluminum alloy, $\varepsilon_{\mathrm{YS}}=0.002[12,22]$. Consequently, it is also possible that local dissolution takes place at the crack tip and film rupture promotes SCC advance with no slip bands emerging on the base metal.

In general, SCC cracks induced by selective dissolution and dislocation motion often propagate along crystal planes. For FCC metals, the slip planes are $\{111\}$. It is suggested by the CEPM and the slip-dissolution model that SCC sometimes occurs on the $\{111\}$ planes of austenitic stainless steel in boiling $\mathrm{MgCl}_{2}$ solutions [5-8, 18-21]. Magnin et al. studied SCC of 316 alloys in the $153{ }^{\circ} \mathrm{C}$ boiling $\mathrm{MgCl}_{2}$ solution, and suggested that transgranular cracking was related to both microshear on the $\{111\}$ planes and microcleavage mainly on the $\{100\}$ planes [6]. Li et al. employed etch-pitting and stereographic observations to determine the SCC crystallography of the same SCC system, finding that cracking occurred predominantly on the $\{100\}$ planes at low $K$ values [23]. In 304L and 310 stainless steels, SCC cracks occurred primarily on the $\{100\}$ planes, while secondary cracks on the $\{110\}$ planes were also found [24-26]. Besides, a number of SCC microcracks initiated at the crossing of two groups of the slip bands and did not follow the $\{111\}$ slip planes $[2,15,27-28]$. Thus, it is probable for SCC cracks to grow along a few low index planes, except the $\{111\}$ slip planes. In other words, without surface slip, preferential dissolution or microcleavage can occur on some crystal planes, such as $\{100\}$ for $304 \mathrm{~L}$ and $\{110\}$ for copper due to the lowest surface energy [24, 29]. Moreover, in crystals with the small Schmid's factor, the low shear stress well below the critical shear stress value, is applied to the $\{111\}$ slip planes, and no slip takes place [5]. In this circumstance, 
other crystal planes are possibly subjected to high normal stress and fracture via local dissolution or microcleavage.

Although lots of research has been conducted on FCC metals slip and crystallography in the past few years, it is essential to correlate SCC and surface slip bands, along with the SCC crystallographic features. In this work, slip bands were investigated on the specimen surfaces with or without short and long SCC cracks. SCC crystallography was characterized by the two-surface trace analysis to determine whether cracks followed the $\{111\}$ slip planes. Finally, microscopic SCC mechanisms of austenitic stainless steel in boiling $\mathrm{MgCl}_{2}$ solutions are discussed at low and high stress levels.

\section{Experimental procedure}

316L SS single crystals were used in this study with the following chemical composition: 0.007 wt.\% C, 17.00 wt.\% Cr, 13.49 wt.\% Ni, 2.54 wt.\% Mo, 0.66 wt.\% Mn, 0.46 wt.\% Si, 0.008 wt.\% P, 0.0056 wt.\% S and Fe balance. The crystals were produced along the [001] direction and machined into $0.7 \mathrm{~mm}$ thick specimens with circle holes $2 \mathrm{~mm}$ in diameter, as shown schematically in Fig. 1. Prior to experiments, the specimens were annealed at $1050{ }^{\circ} \mathrm{C}$ for $30 \mathrm{~min}$ in argon, water-quenched, ground using 2000 grit emery paper, electrochemically thinned to about $0.5 \mathrm{~mm}$ in solution

containing $\mathrm{H}_{3} \mathrm{PO}_{4}, \mathrm{H}_{2} \mathrm{SO}_{4}, \mathrm{CrO}_{3}$ and $\mathrm{C}_{2} \mathrm{H}_{6} \mathrm{O}_{2}$ (glycol), degreased with acetone in an ultrasonic cleaner and washed with deionized water. After the pretreatment, the samples were placed into a glass container filled with a boiling 45 wt.\% $\mathrm{MgCl}_{2}$ 
solution. Normal stress of either $20 \mathrm{MPa}$ or $40 \mathrm{MPa}$, calculated in terms of the narrowest section $\left(2 \times 0.5 \mathrm{~mm}^{2}\right)$, was applied to the specimens. All experiments were carried out under an open circuit condition using a constant load weight-type apparatus with a cooling system, two 316L SS single crystal pins and two silica grips.

After 200-300 hours, SCC cracks grew to a certain size and specimens were taken out from the glass container. Some specimens were ultrasonically cleaned in deionized water as well as $5 \mathrm{wt} . \% \mathrm{HCl}+2 \mathrm{~g} / \mathrm{L}$ hexamethylenetetramine mixture to remove corrosion products from the specimen surface. Both cleaned and virgin samples were employed to examine the slip bands and SCC cracks by scanning electron microscopy (SEM). To correlate surface slip and SCC propagation, it was checked whether the slip bands appeared in nucleation areas and near crack tips of short and long cracks. The two-surface trace analysis was utilized to characterize crystalline planes of the 316L single crystal cracking surfaces. As seen in Fig. 2, the $\left(h_{0} k_{0} l_{0}\right)\left[u_{0} v_{0} w_{0}\right]$ crystallography of the first surface containing an SCC crack was determined by electron backscatter diffraction (EBSD). The angles $\theta_{1}$ and $\theta_{2}$ between the crack and the $\left[u_{0} v_{0} w_{0}\right]$ crystal orientation were measured, and the $[u v w]$ crack orientation was calculated using Eqs. (1) and (2). The cosine of the $\theta$ angle formed by the two $\left[u_{1} v_{1} w_{1}\right]$ and $\left[u_{2} v_{2} w_{2}\right]$ crystal orientations is:

$$
\cos \theta=\frac{u_{1} u_{2}+v_{1} v_{2}+w_{1} w_{2}}{\sqrt{u_{1}^{2}+v_{1}^{2}+w_{1}^{2}}+\sqrt{u_{2}^{2}+v_{2}^{2}+w_{2}^{2}}}
$$

The relationship between the $\left(h_{1} k_{1} l_{1}\right)$ crystal plane and the $\left[u_{1} v_{1} w_{1}\right]$ crystal orientation on the plane is:

$$
u_{1} h_{1}+v_{1} k_{1}+w_{1} l_{1}=0
$$


Subsequently, the second surface parallel to the first one was obtained by removing a surface layer or directly extracting an X-ray computed tomographic slice. This way, the angles $\varphi_{1}$ and $\varphi_{2}$ between the cracking plane and the first surface were identified, and the cracking ( $h k l$ ) plane was determined according to Eqs. (2) and (3). The cosine of the angle $\varphi$ formed by the two $\left(h_{1} k_{1} l_{1}\right)$ and $\left(h_{2} k_{2} l_{2}\right)$ crystal planes is:

$$
\cos \varphi=\frac{h_{1} h_{2}+k_{1} k_{2}+l_{1} l_{2}}{\sqrt{h_{1}^{2}+k_{1}^{2}+l_{1}^{2}}+\sqrt{h_{2}^{2}+k_{2}^{2}+l_{2}^{2}}}
$$

In addition, Eq. (3) was also used to estimate the relationship between the obtained cracking plane and low index crystal plane, such as $\{100\}$ and $\{111\}$.

\section{Experimental results}

\subsection{Surface slip bands}

The effects of surface slip on SCC cracks were investigated using SEM. At the high normal stress of $40 \mathrm{MPa}$, slip bands were able to appear on sample surfaces, one of which is shown in Fig. 3(a). It is found that the slip band was corroded and lots of microvoids were distributed at the slip band. However, there was no slip band on the surface at the $20 \mathrm{MPa}$ stress level, as shown in Fig. 3(b). Similarly, as seen in Fig. 4, the slip bands did not emerge near the tip of Crack 1 on the two surfaces of the cracked sample subjected to the $20 \mathrm{MPa}$ normal stress, meaning that SCC initiation and propagation could take place without the surface slip bands for the low load conditions. Then, the surface slip was examined in nucleation areas and near the crack 
tips of the specimens under the $20 \mathrm{MPa}$ normal stress, shown in Fig. 5 and Fig. 6. As seen in Fig. 5, the Crack 2 was about $0.1 \mathrm{~mm}$ in length and there was no slip band around the crack. Similarly, on the virgin specimen in Fig. 6, slip bands did not emerge in the nucleation area and near the tip of approximately $0.5 \mathrm{~mm}$ long Crack 3. The Crack 4 was roughly $1.5 \mathrm{~mm}$ in length and the slip bands were formed near the crack tip rather than in the nucleation area of the Crack 4 . Thus, the Crack 4 did not propagate along the slip bands, as seen in Fig. 6(a), (d) and (e). As a consequence, the surface slip was capable of forming again when the crack extended to a critical size in the specimen subjected to low applied stress levels. The sample and the fracture surface morphology was observed on the same specimen loaded with the $20 \mathrm{MPa}$ normal stress, shown in Fig. 7 and Fig. 8, respectively. No surface slip bands could be found in the area between labels 1 and 2 in Fig. 7(a), as seen in Fig. 7(b). Then, the fracture surface of the same area was observed by SEM, finding that no macroscopic deformation occurred in the specimen and lots of microsteps together with several tear ridges are seen in Fig. 8(a) and (b). The areas between the labels 2 and 3, and between 2' and 3' were examined, shown in Fig. 7(a), (c) and Fig. 8(a), (c), respectively. Numerous slip bands, microsteps and tear ridges were present and the specimen was slightly deformed.

Finally, the crack propagated in the area between labels 3 and 4. As seen in Fig. 7(a), (d) and Fig. 8(a), (d), some secondary cracks and necking were detected in addition to the surface slip bands, microsteps and tear ridges, while cracks did not extend along the surface slip bands. 


\subsection{SCC crystallographic features}

The two-surface trace analysis was used to characterize crystallographic feathers of the cracking planes. As seen in Fig. 9, the first surface containing microcracks was the (014) crystal plane detected by EBSD. The angle between the [24ī] crystal orientation and the microcracks was either $78^{\circ}$ or $102^{\circ}$. According to Eqs. (1) and (2), the relationships between the $[u v w]$ crystal orientation and the microcracks on the (014) crystal plane are:

$$
\begin{gathered}
\frac{(2 \times u)+(4 \times v)+[(-1) \times w]}{\sqrt{2^{2}+4^{2}+(-1)^{2}} \times \sqrt{u^{2}+v^{2}+w^{2}}}=\cos 78^{\circ} \text { or } \cos 102^{\circ} \\
0 \times u+1 \times v+4 \times w=0
\end{gathered}
$$

Thus, the microcrack orientation was either $[1 \overline{0.24} 0.06]$ or $[1 \overline{0.76} 0.19]$. Then, a 7 $\mu \mathrm{m}$ thick layer was removed by mechanical polishing, and the newly exposed surface was the second surface, shown in Fig. 9(b). On the first and the second surfaces, the distances between the labels $\mathbf{M}_{1}$ and $\mathbf{M}_{1}{ }^{\prime}$ and the microcrack were measured, shown schematically in Fig. 9(c). The tilt angle between the cracking plane and the first surface were determined as either $7^{\circ}$ or $183^{\circ}$. In terms of Eqs. (2) and (3), the expressions for the $(h k l)$ cracking plane are:

$$
\begin{gathered}
u h+v k+w l=0 \\
\frac{(0 \times h)+(1 \times k)+(4 \times l)}{\sqrt{0^{2}+1^{2}+4^{2}} \times \sqrt{h^{2}+k^{2}+l^{2}}}=\cos 7^{\circ} \text { or } \cos 183^{\circ}
\end{gathered}
$$

When the microcrack orientation $[u v w]$ was $[1 \overline{0.24} 0.06]$, the $(h k l)$ cracking plane was either $(0.030 .381)$ or $(\overline{0.03} 0.131)$, while the $[1 \overline{0.76} 0.19]$ microcrack orientation corresponded to either $(0.080 .361)$ or $(\overline{0.08} 0.151)$. Using the same 
method, the crystallographic features of the crack in Fig. 10 were checked. In light of Eqs. (1-3), the $\left(h^{\prime} k^{\prime} l^{\prime}\right)$ cracking plane and the $\left[u^{\prime} v^{\prime} w^{\prime}\right]$ crack orientation on the first (0 01) surface can be expressed as:

$$
\begin{gathered}
\frac{\left(5 \times u^{\prime}\right)+\left(1 \times v^{\prime}\right)+\left(0 \times w^{\prime}\right)}{\sqrt{5^{2}+1^{2}+0^{2}} \times \sqrt{u^{\prime 2}+v^{\prime 2}+w^{\prime 2}}}=\cos 96^{\circ} \text { or } \cos 84^{\circ} \\
0 \times u^{\prime}+0 \times v^{\prime}+1 \times w^{\prime}=0 \\
u^{\prime} h^{\prime}+v^{\prime} k^{\prime}+w^{\prime} l^{\prime}=0 \\
\frac{\left(0 \times h^{\prime}\right)+\left(0 \times k^{\prime}\right)+\left(1 \times l^{\prime}\right)}{\sqrt{0^{2}+0^{2}+1^{2}} \times \sqrt{h^{\prime 2}+k^{\prime 2}+l^{\prime 2}}}=\cos 90^{\circ}
\end{gathered}
$$

Therefore, the $\left[u^{\prime} v^{\prime} w^{\prime}\right]$ crack orientation was either [0.3210] or [0.0910], and the corresponding $\left(h^{\prime} k^{\prime} l^{\prime}\right)$ cracking plane was either (10.320) or (10.090). According to these calculations, the microcrack and the crack did not propagate along the low index crystal planes, for instance $\{100\}$ and $\{111\}$. However, there was a certain error when measuring the angles, and corresponding correlations of the angle between the cracking planes and the low index crystal planes were estimated based on Eq. (3). For the crack, there is a $5^{\circ}$ angle between the (100) and (10.090) planes, and the cracking plane was approximately (100). Similarly, it was possible for the microcrack to advance along the (001) plane due to the $8^{\circ}$ angle between the $(001)$ and the $(\overline{0.03} 0.131)$ planes. However, the minimal angles between the obtained crack and the microcrack with respect to the $\{111\}$ planes were $44^{\circ}$ and $39^{\circ}$, respectively. As a consequence, the crack and the microcrack did not grow along the $\{111\}$ planes. 


\section{Discussion}

\subsection{Surface slip bands formation}

Surface slip bands usually accompany initiation and propagation of SCC cracks in specimens subjected to loads. Experimental results of this paper show that the surface slip occurred at the high stress levels and near the long crack tip, but the surface slip bands did not form at the low stress level or around the short SCC cracks. In theory, the $\{111\}<110>$ slip system in FCC metals starts when the shear stress, $\tau$, applied to the $\{111\}$ slip plane along the $<110>$ direction is equal to or greater than the critical shear stress, $\tau_{\mathrm{C}}$. The shear stress, $\tau$, is represented by:

$$
\tau=\sigma \cos \phi \cos \lambda=\sigma \mu
$$

where $\sigma$ is the applied stress, $\phi$ is the angle between the applied stress axis and the normal line of the $\{111\}$ slip plane, $\lambda$ is the angle between the applied stress and the $\langle 110\rangle$ slip direction, and $\mu=\cos \phi \cos \lambda$ is the Schmidt's factor with the maximum value of 0.5. Based on Eq. (12), the shear stress depends on the product of the applied stress and the Schmidt's factor. As a result, when $\mu$ is constant and $\sigma$ is very low, or when $\sigma$ is constant and $\mu$ is quite small, $\tau$ is lower than $\tau_{\mathrm{C}}$.

For the $316 \mathrm{~L}$ austenitic stainless steel, $\tau_{\mathrm{C}}$ is approximately $3.2 \times 10^{-4}$ times the shear modulus of $G=72 \mathrm{GPa}$, about $23 \mathrm{MPa}$ [30]. At the $20 \mathrm{MPa}$ normal stress level, the maximum stress is $42.8 \mathrm{MPa}$, considering local stress concentration [16]. Substituting the maximum stress and the maximum Schmidt's factor in Eq. (12) yields the shear peak stress, $\tau_{\max }=21.4 \mathrm{MPa}$, which is lower than $\tau_{\mathrm{C}}$. As a consequence, the 
surface slip bands can not form under the low load, for example on the specimen surfaces in Fig. 3(b). However, $\tau_{\max }$ is up to $42.8 \mathrm{MPa}$ at the $40 \mathrm{MPa}$ normal stress level, and glide can occur on the specimen surfaces, seen in Fig. 3(a). For the cracked specimens subjected to the $20 \mathrm{MPa}$ normal stress, the stressed sections perpendicular to the tensile direction become narrow and the stresses increase at the crack tips once the cracks initiate. When the cracks grow to the critical size, the shear stresses applied to the $\{111\}$ planes exceed $\tau_{\mathrm{C}}$ and the slip systems start. With crack growth, the slip bands can form around the long SCC cracks, similar to the Crack 4, but do not appear near the short SCC cracks, such as Cracks 2 and 3. In a word, the formation of the surface slip bands depends directly on the shear stresses applied to the $\{111\}$ slip planes, rather than SCC initiation and propagation.

\subsection{SCC microscopic mechanisms}

It is well known that microcleavage, microshear and local dissolution are primary SCC mechanisms [5-8, 15, 18-21]. In our experiments, the SCC cracks could nucleate and propagate without surface slip, and the surface cracks, possibly on the $\{100\}$ planes, did not propagate along the $\{111\}$ slip planes. Based on the observations of the fracture surface without surface slip bands, only several tear ridges were found with numerous microsteps. Thus, the initiation and propagation of most SCC cracks may not be induced by the microshear along the $\{111\}$ planes under the low load conditions. It is considered that the microcleavage and the local dissolution occur on some crystal planes, leading to the SCC advance at the micron 
scale. When the surface slip takes place, lots of tear ridges along with microsteps are distributed on the fracture surface and a few microvoids are located at the surface slip band. As a result, apart from the microcleavage and the local dissolution, the microshear is also one of the main SCC mechanisms at the high stress level.

In the brittle fracture mode, the microcleavage can induce SCC initiation and propagation, regardless of the slip bands appearing on the specimen surfaces. Under these circumstances, the Griffith criterion for the crack advance becomes valid at a local scale [5], expressed as:

$$
K_{\text {IC }}=\sqrt{\frac{2 \gamma E}{\left(1-v^{2}\right)}}
$$

where $K_{\mathrm{IC}}$ is the fracture toughness, $\gamma$ is the surface energy, $E$ is the elastic modulus and $v$ is the Poisson's ratio. In terms of the stress intensity factor, $K_{\mathrm{I}}$, the crack propagates when $K_{\mathrm{I}} \geq K_{\mathrm{IC}}$. For austenitic stainless steel, the $\{100\}$ planes have the lowest surface energy [24, 29], so the minimum stress is needed to fracture the planes and the SCC cracks tend to appear on the $\{100\}$ planes. On the other hand, the presence of dislocations modifies the stress intensity factor at the crack tip [5]:

$$
K_{\mathrm{I}}=K_{\mathrm{Ia}}+\sum_{D} K_{\mathrm{D}}
$$

where $K_{\mathrm{Ia}}$ is the applied stress intensity factor and $K_{\mathrm{D}}$ is the contribution of each dislocation. If dislocations pile up ahead of the crack tip, the local stress concentration is formed, facilitating the microcleavage on some crystal planes. The microscopic mechanism of SCC via microcleavage is shown schematically in Fig. 11. Based on the acidic environment and low surface potential at the crack tip [31-32], local dissolution 
can take place on the cracking plane, as shown in Fig. 11. The newly exposed metal or dislocations emerging on the surface act as anodes and are subject to chemical attack, which leads to the SCC advance. The microvoids at the slip band and some of the microsteps in the fracture surface provide evidences for this kind of microscopic mechanism. Usually corrosion and microcleavage are considered separately in most SCC models. Their synergistic effects should be taken into account to fully explain the fracture mechanism. That is, the local dissolution induces new stress concentration, favoring microcleavage of the crystal planes, which exposes fresh cracking planes, promoting corrosion at the crack tip. As a consequence, the environmental fracture results from the interactions between the microcleavage and the local dissolution. At the high stress levels, the microshear is another factor determining SCC initiation and propagation. This way, plastic energy dissipation is large and more energy is needed to grow a crack. Thus, it is possible for the SCC crack to form by the microscopic mechanism under the high load, while the microshear occurs rarely at the low stress levels. In short, the microleavage and the local dissolution synergistically induce the SCC advance on the crystal planes, like $\{100\}$. For the crack subjected to the high stresses, the microshear is one of the primarily microscopic SCC mechanisms.

\section{Conclusions}

The surface slip occurred at high stress levels, but slip bands did not emerge at the low stress levels or around short SCC cracks. The surface slip depended on the shear stresses on the $\{111\}$ slip planes, rather than on the SCC initiation and 
propagation. The cracks did not necessarily propagate along the $\{111\}$ slip planes. Other crystal faces, for instance $\{100\}$, were also possibly the SCC cracking planes. Numerous microsteps were distributed on the fracture surface with and without the surface slip bands, and there were lots of microvoids at the slip band, so the microcleavage and the local dissolution synergistically lead to the SCC advance on some crystal planes, like $\{100\}$. When the slip bands appeared on the specimen surfaces, many tear ridges were found, along with necking. As a result, microshear is one of the primarily microscopic SCC mechanisms at the high stress levels.

\section{Acknowledgements}

The authors wish to thank You $\mathrm{He}$, Yanan $\mathrm{Fu}$ and Honglan Xie from the Shanghai Sychrotron Radiation Facility for their experimental help. The authors also acknowledge funding provided by the National Nature Science Foundation of China under grant 51432004 and the National Key S\&T Special Projects under the grant 2011zx06901-017. AV acknowledges support from the National Science Foundation (IRES1358088).

\section{References}

[1] H.L. Logan, Film-rupture mechanism of stress corrosion, J. Res. Natl. Bur. Stand. 48 (1952) 99-105.

[2] L.J. Qiao, X. Mao, J.L. Luo, Micromechanics of stress corrosion cracking of 
single-crystal austenitic type 321 stainless steel under mode II loading, Corrosion 52 (1996) 927-933.

[3] J.X. Li, W.Y. Chu, Y.B. Wang, L.J. Qiao, In situ TEM study of stress corrosion cracking of austenitic stainless steel, Corros. Sci. 45 (2003) 1355-1365.

[4] M.R. Wenman, K.R. Trethewey, S.E. Jarman, P.R. Chard-Tuckey, A finite-element computational model of chloride-induced transgranular stress-corrosion cracking of austenitic stainless steel, Acta Mater. 56 (2008) 4125-4136.

[5] J.P. Chateau, D. Delafosse, T. Magnin, Numerical simulations of hydrogendislocation interactions in fcc stainless steels: Part II: hydrogen effects on crack tip plasticity at a stress corrosion crack, Acta Mater. 50 (2002) 1523-1538.

[6] T. Magnin, R. Chieragatti, R. Oltra, Mechanism of brittle fracture in a ductile 316 alloy during stress corrosion, Acta Metall. Mater. 38 (1990) 1313-1319.

[7] T. Magnin, R. Chieragatti, R. Oltra, Mechanism of brittle fracture in a ductile 316 alloy during stress corrosion, Acta Metall. Mater. 38 (1990) 1313-1319.

[8] R.C. Newman, C. Healey, Stability, Validity and sensitivity to input parameters of the slip-dissolution model for stress-corrosion cracking, Corros. Sci. 49 (2007) 4040-4050.

[9] H.W. Pickering, P.R. Swann, Electron metallography of chemical attack upon some alloys susceptible to stress corrosion cracking, Corrosion 19 (1963) 373t-389t.

[10] M.R. Louthan Jr., Initial stage of stress corrosion cracking in austenitic stainless steels, Corrosion 21 (1965) 288-294.

[11] D.G. Kolman, J.R. Scully, Continuum mechanics characterization of plastic deformation-induced oxide film rupture, Philos. Mag. A 79 (1999) 2313-2338. 
[12] E.M. Gutman, An inconsistency in "film rupture model" of stress corrosion cracking, Corros. Sci. 49 (2007) 2289-2302.

[13] K.R. Trethewey, Some observations on the current status in the understanding of stress-corrosion cracking of stainless steels, Mater. Design 29 (2008) 501-507.

[14] M.M. Hall Jr., Film rupture model of aqueous stress corrosion cracking under constant and variable stress intensity factor, Corros. Sci. 51 (2009) 225-233.

[15] L.J. Qiao, K.W. Gao, J.L. Luo, Discontinuous surface cracks during stress corrosion cracking of stainless steel single crystal, Corros. Sci. 53 (2011) $3509-3514$.

[16] L.K. Zhu, Y. Yu, L.J. Qiao, A.A. Volinsky, Stainless steel pitting and early-stage stress corrosion cracking under ultra-low elastic load, Corros. Sci. 77 (2013) 360-368.

[17] L.K. Zhu, Y. Yu, J.X. Li, L.J. Qiao, A.A. Volinsky, Stress corrosion cracking under low stress: Continuous or discontinuous cracks?, Corros. Sci. 80 (2014) $350-358$.

[18] J.P. Chateau, D. Delafosse, T. Magnin, Numerical simulations of hydrogendislocation interactions in fcc stainless steels: Part I: hydrogen-dislocation interactions in bulk crystals, Acta Mater. 50 (2002) 1507-1522.

[19] D. Delafosse, T. Magnin, Hydrogen induced plasticity in stress corrosion cracking of engineering system, Eng. Fract. Mech. 68 (2001) 693-729.

[20] T. Magnin, A. Chambreuil, B. Bayle, The corrosion-enhanced plasticity model for stress corrosion cracking in ductile fcc alloys, Acta Mater. 44 (1996) 1457-1470.

[21] W.F. Flanagan, P. Bastias, B.D. Lichter, A theory of transgranular stress-corrosion 
cracking, Acta Metall. Mater. 39 (1991) 695-705.

[22] W.D. Callister Jr., Materials Science and Engineering, John Willey \& Sons, Inc., 1985.

[23] S. Li, J.I. Dickson, J.P. Bailon, The influence of the stress intensity factor on the fractography of stress corrosion cracking of 316 stainless steel, Mater. Sci. Eng. A119 (1989) 59-72.

[24] E.I. Meletis, R.F. Hochman, The crystallography of stress corrosion cracking in face centered cubic single crystals, Corros. Sci. 24(1984) 843-862.

[25] E.I. Meletis, R.F. Hochman, A review of the crystallography of stress corrosion cracking, Corros. Sci. 26 (1986) 63-77, 79-90.

[26] J.I. Dickson, D. Groulx, S. Li, The fractography of stress corrosion cracking of 310 stainless steel: crystallographic aspects and the influence of stress intensity factor, Mater. Sci. Eng. 94 (1987) 155-173.

[27] K.W. Gao, L.J. Qiao, W.Y. Chu, Fractographic study of SCC of 321 austenitic stainless steel single crystal, Acta Metallurgica Sinica 34 (1998) 888-891.

[28] H. Uchida, M. Yamashita, S. Inoue, K. Koterazawa, In-situ observation of crack nucleation and growth during stress corrosion by scanning vibrating electron technique, Mater. Sci. Eng. A319-321 (2001) 496-500.

[29] G. Caglioti, G. Rizzi, J.C. Bilello, Surface energy for brittle fracture in metals from phonon frequencies, J. Appl. Phys. 42 (1971) 4271-4276.

[30] X.H. Cheng, Q.X. Dai, A.D. Wang, Stacking-fault energy and $\varepsilon$-martensite transformation of austenitic steels, Journal of Iron and Steel Research 15 (2003) 
$55-58$.

[31] L. Qiao, X. Mao, Thermodynamic analysis on the role of hydrogen in anodic stress corrosion cracking, Acta Metall. Mater. 43 (1995) 4001-4006.

[32] H. Masuda, SKFM observation of SCC on SUS304 stainless steel, Corros. Sci. 49 (2007) 120-129.

\section{Figure Captions}

Fig. 1. Schematics of 316L stainless steel single crystal specimens (dimensions are in $\mathrm{mm})$.

Fig. 2. Schematic diagram of the two-surface trace analysis characterizing the crystallography of the $316 \mathrm{~L}$ single crystal cracking plane, where $\mathrm{M}$ and $\mathrm{M}$ ' are the labels on the first and second surfaces, respectively. $\theta_{1}$ and $\theta_{2}$ are the angles between the crack and the $\left[u_{0} v_{0} w_{0}\right]$ crystal orientation, while $\varphi_{1}$ and $\varphi_{2}$ are the angles between the cracking plane and the first surface. The $\left[u_{0} v_{0} w_{0}\right]$ crystallography of the first surface was determined by electron backscatter diffraction.

Fig. 3. Surface morphology of the specimens with cleaned off corrosion products, subjected to normal stress of: (a) $40 \mathrm{MPa}$ and (b) $20 \mathrm{MPa}$. The slip band was corroded 
and lots of microvoids emerged at the slip band. However, there was no slip band on the surface in Fig. 3(b).

Fig. 4. Crack 1 tip morphology near (a) the front sample surface and (b) the back sample surface of the etched specimen subjected to $20 \mathrm{MPa}$ normal stress. On the two surfaces, the slip bands did not emerge near the tip of the Crack 1.

Fig. 5. (a) The whole surface morphology of Crack 2 in a cleaned specimen subjected to $20 \mathrm{MPa}$ normal stress; (b) Crack 1 nucleation area surface morphology; (c) surface morphology near the tip of the Crack 1. It is found that SCC initiation and propagation took place without the surface slip bands at low load.

Fig. 6. (a) The whole original surface of Cracks 3 and 4 in a specimen subjected to 20 MPa normal stress; (b) Crack 3 nucleation area surface morphology; (c) surface morphology near the tip of the Crack 3; (d) Crack 4 nucleation area surface morphology; (e) the surface morphology near the tip of the Crack 4. No surface slip band was observed near the Crack 3, while the slip bands emerged around the tip of the Crack 4.

Fig. 7. (a) The whole surface morphology of the fractured specimen subjected to 20 MPa normal stress; (b) partial surface morphology of the area between labels 1 and 2 
in (a); (c) partial surface morphology of the area between labels 2 and 3 in (a); (d) partial surface morphology of the area between labels 3 and 4 in (a), some slip bands are visible above the arrow and others are coated by corrosion products on the right of the arrow.

Fig. 8. (a) Fracture surface of the specimen in Fig. 7; (b) partial fracture surface of the area between labels 1' and 2' in (a); (c) partial fracture surface of the area between labels 2' and 3' in (a); and (d) partial fracture surface of the area between labels 3' and 4' in (a). Microsteps, tear ridges or secondary cracks are distributed on the fracture surface.

Fig. 9. Morphology of (a) the original surface and (b) mechanically polished surface after removing a $7 \mu \mathrm{m}$ thick layer, and (c) schematic diagram of the angle formed by the microcrack and the first surface between the labels $\mathrm{M}_{1}$ and $\mathrm{M}_{1}$ '. The calculated result shows that the microcrack possibly advanced along the (001) crystal plane.

Fig. 10. Surface morphology of the two X-ray computed tomographic slices (a) and (b) $37 \mu \mathrm{m}$ away from each other, and (c) schematic diagram of the angle formed by the crack and the first surface between the labels $\mathrm{M}_{2}$ and $\mathrm{M}_{2}$ ' at the centers of the left edges. It is found that the crack plane might be the (100) crystal plane. 
Fig. 11. Schematics of the microscopic SCC mechanisms by microcleavage, microshear and localized dissolution: (a) before the fracture of the cracking plane, like $\{100\}$ and (b) the microcrack formation. At low loads, the synergistic effects of microcleavage and local dissolution induced SCC advance on crystal planes like $\{100\}$. Meanwhile, microshear was an additional SCC microscopic mechanism at high stress levels. 
Figure 1

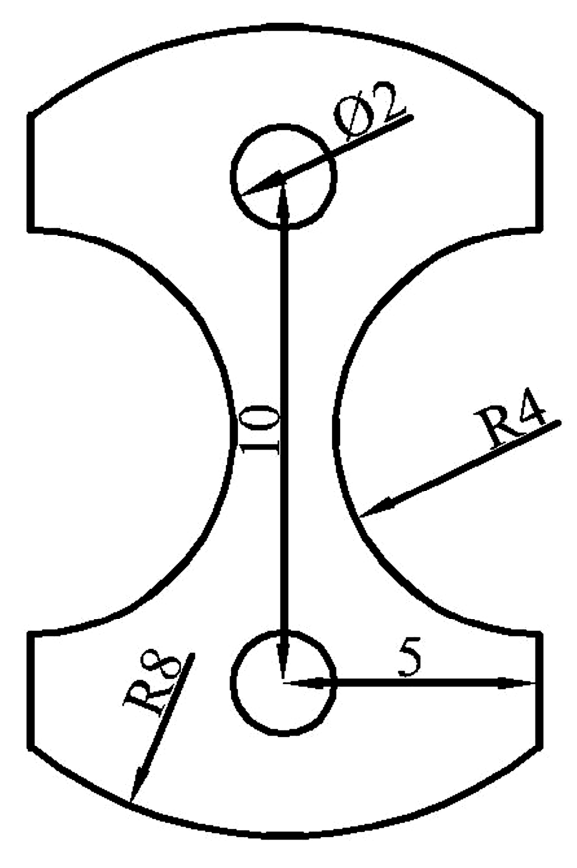


Figure 2

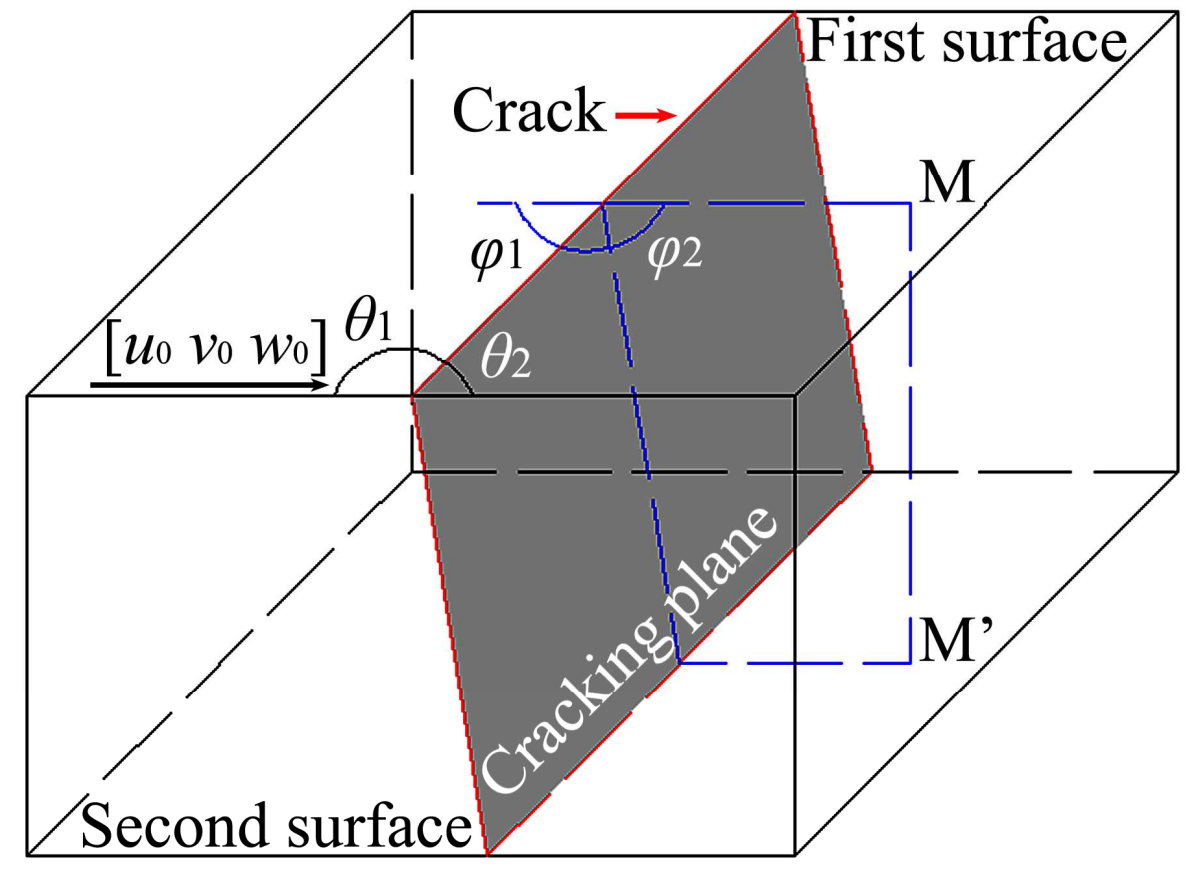


Figure 3
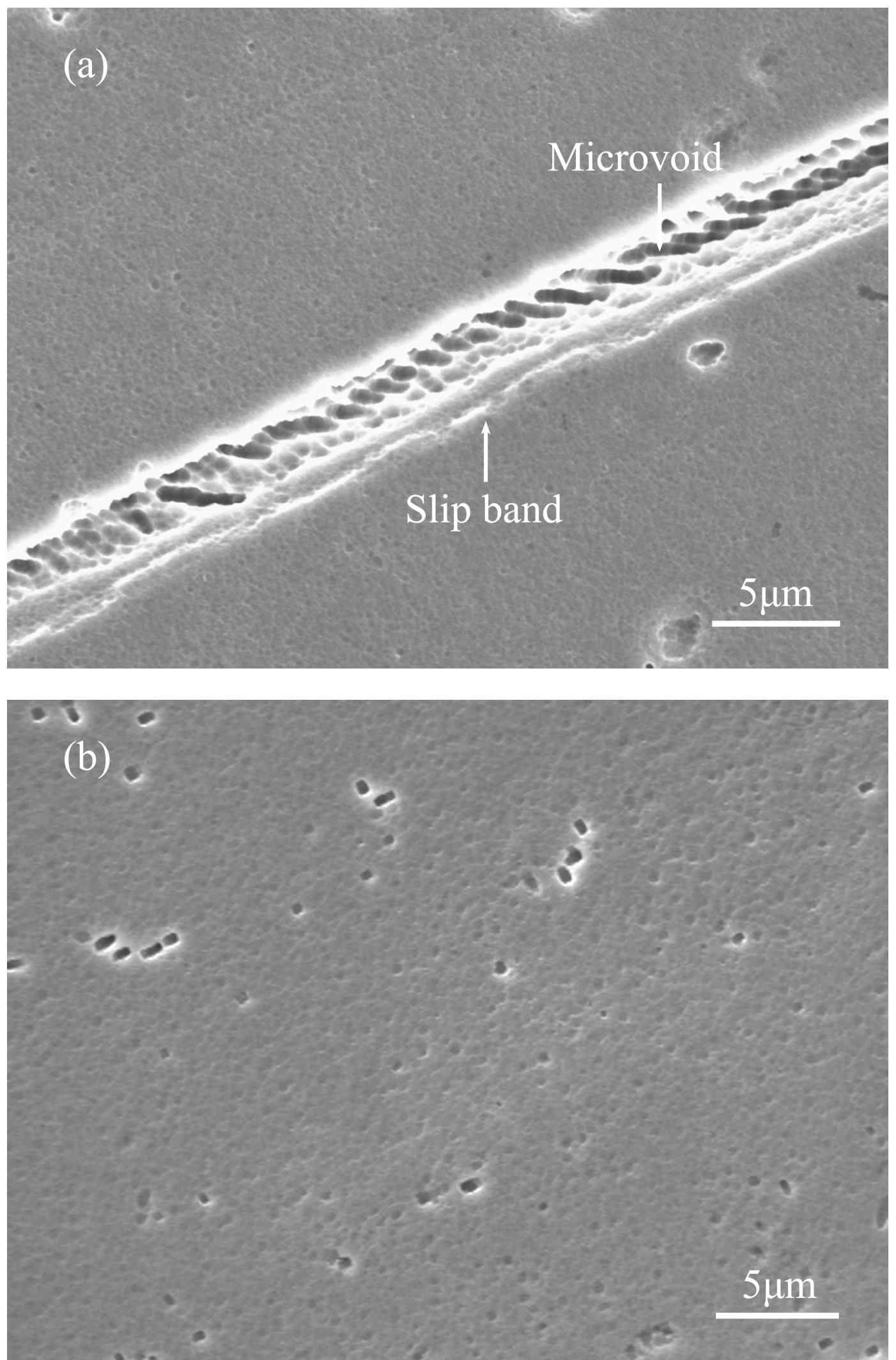
Figure 4

(a)

10um

(b) 
Figure 5
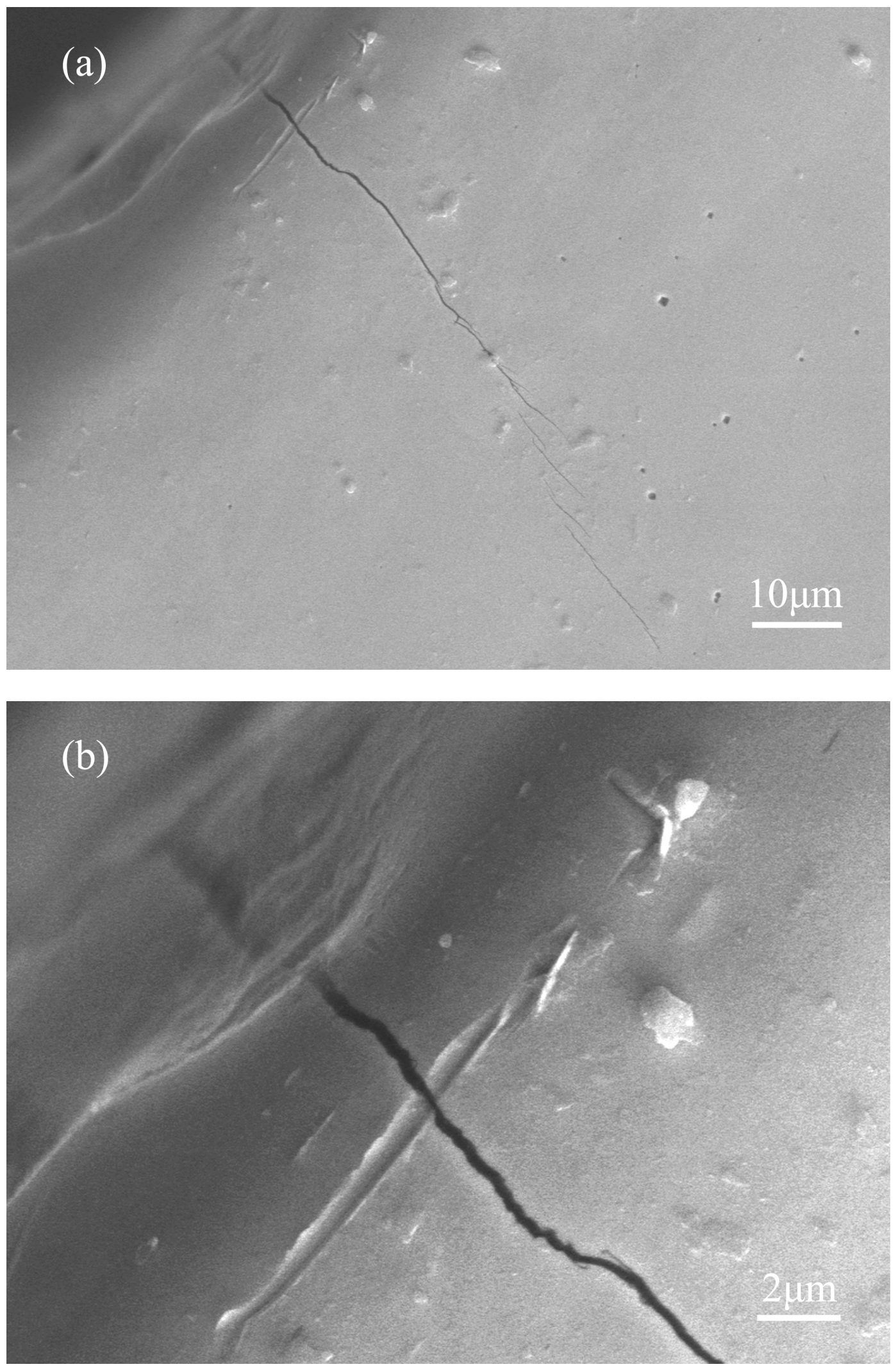


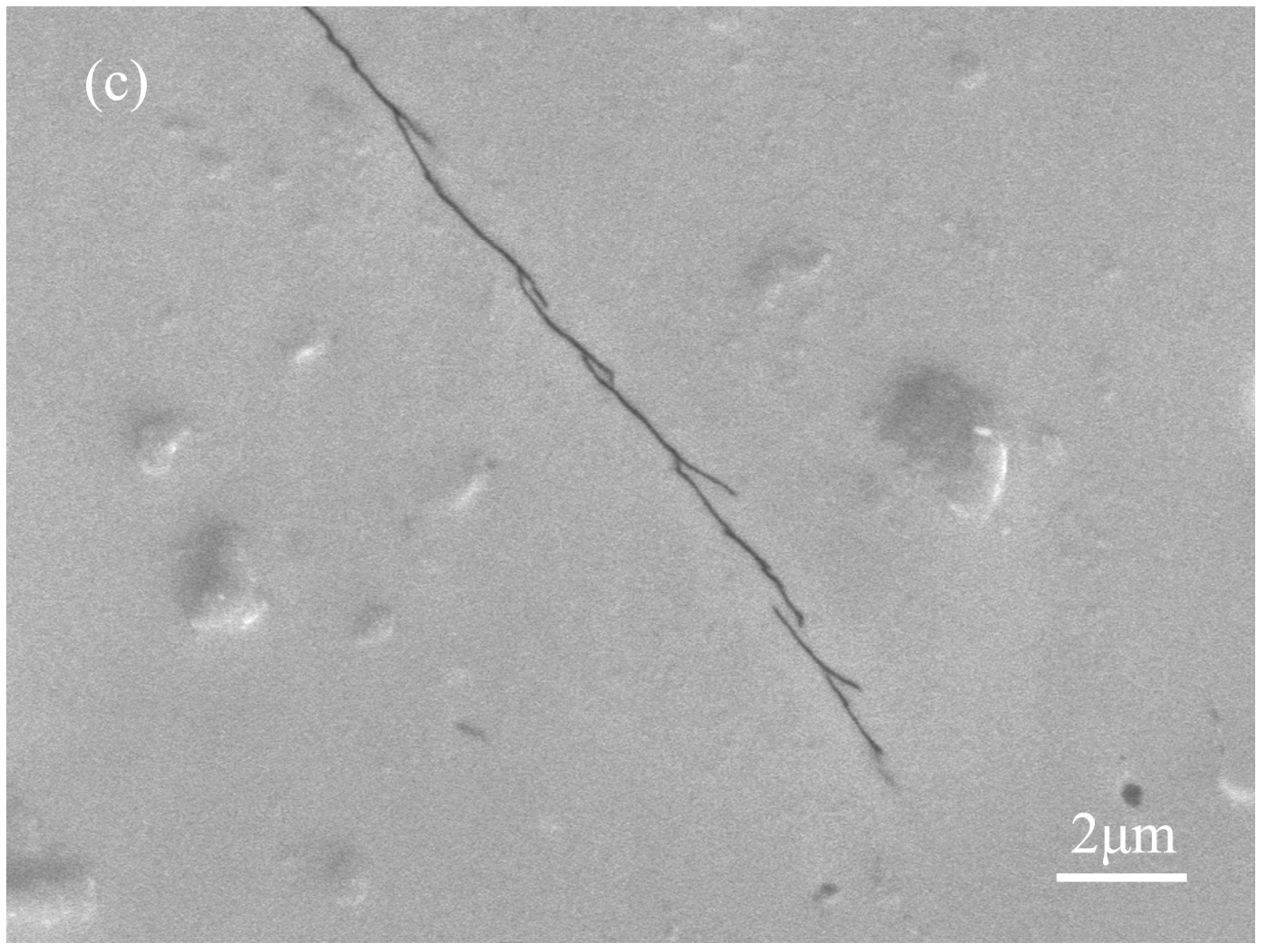


Figure 6
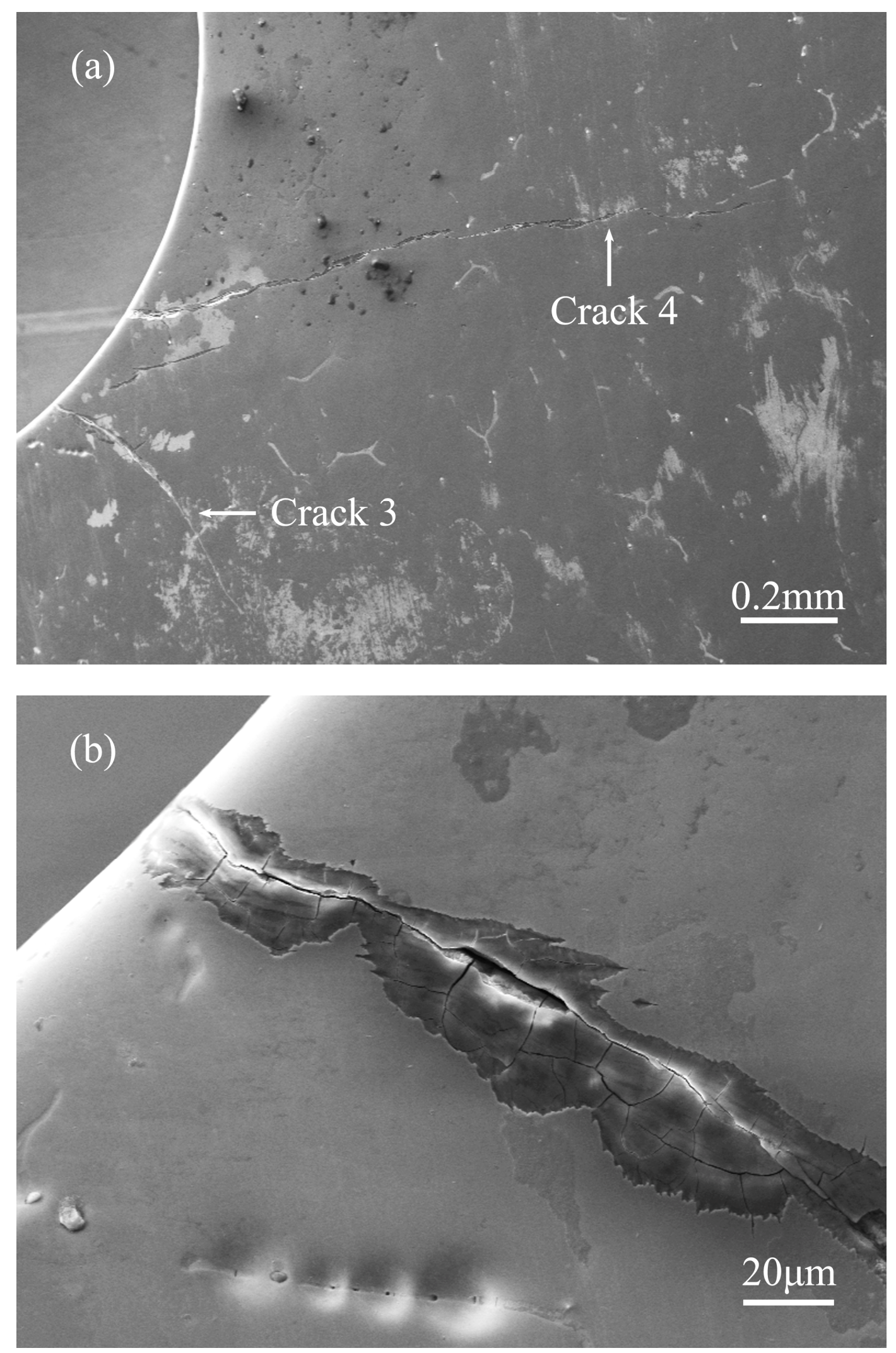

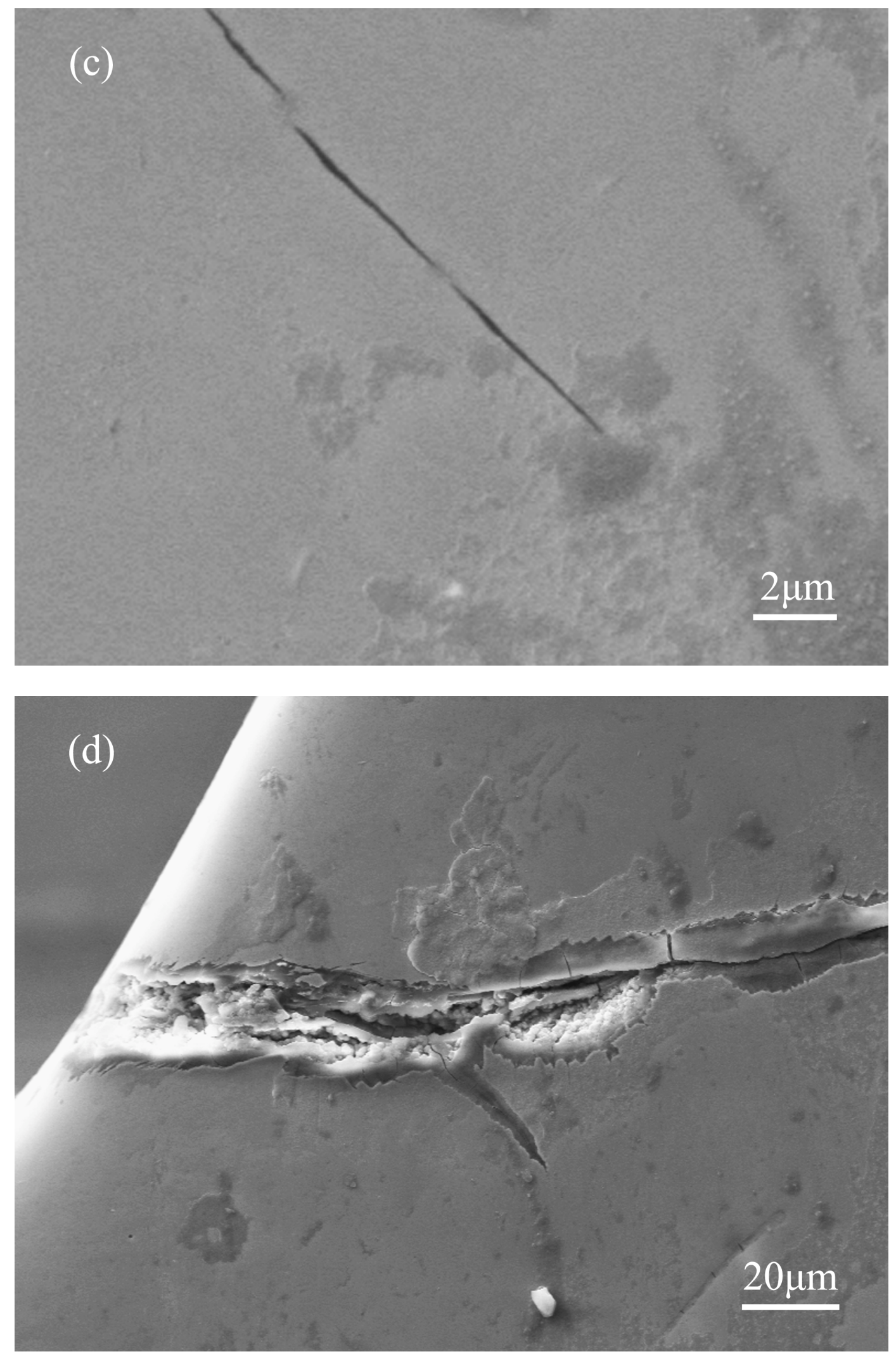
(e)

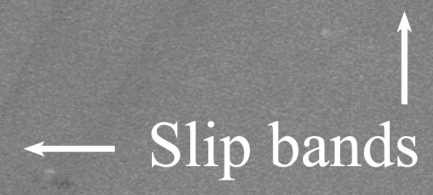


Figure 7
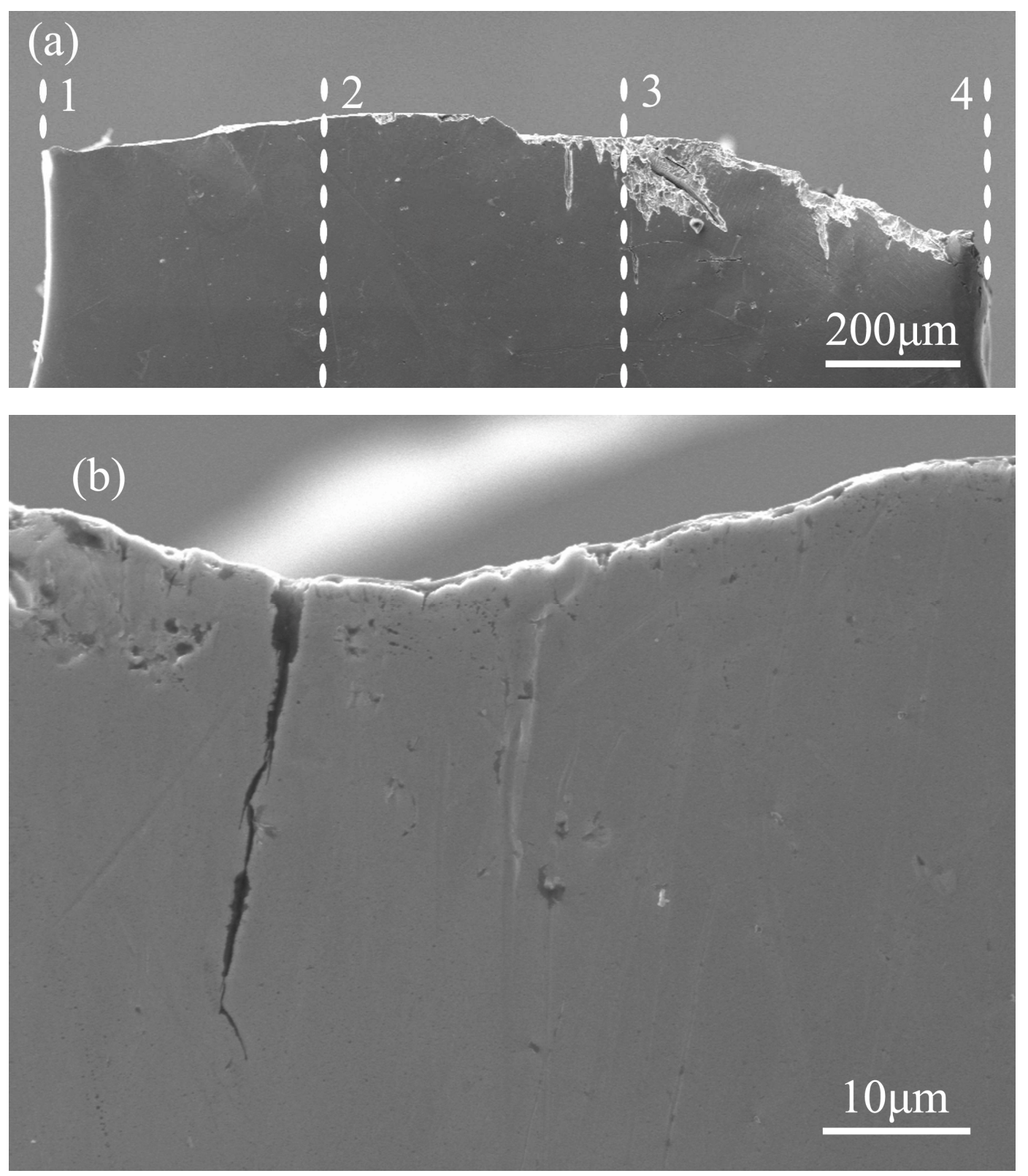

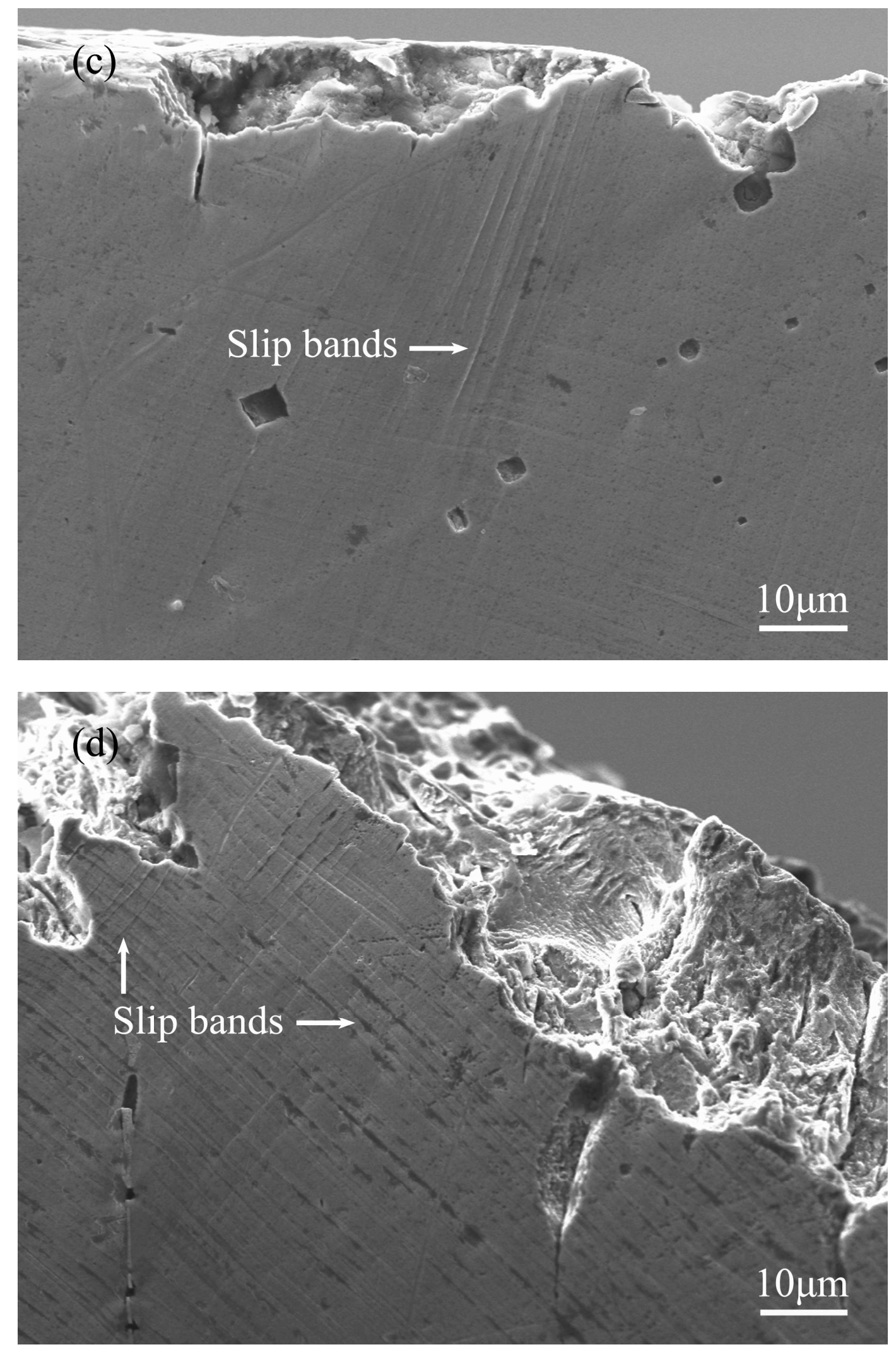
Figure 8
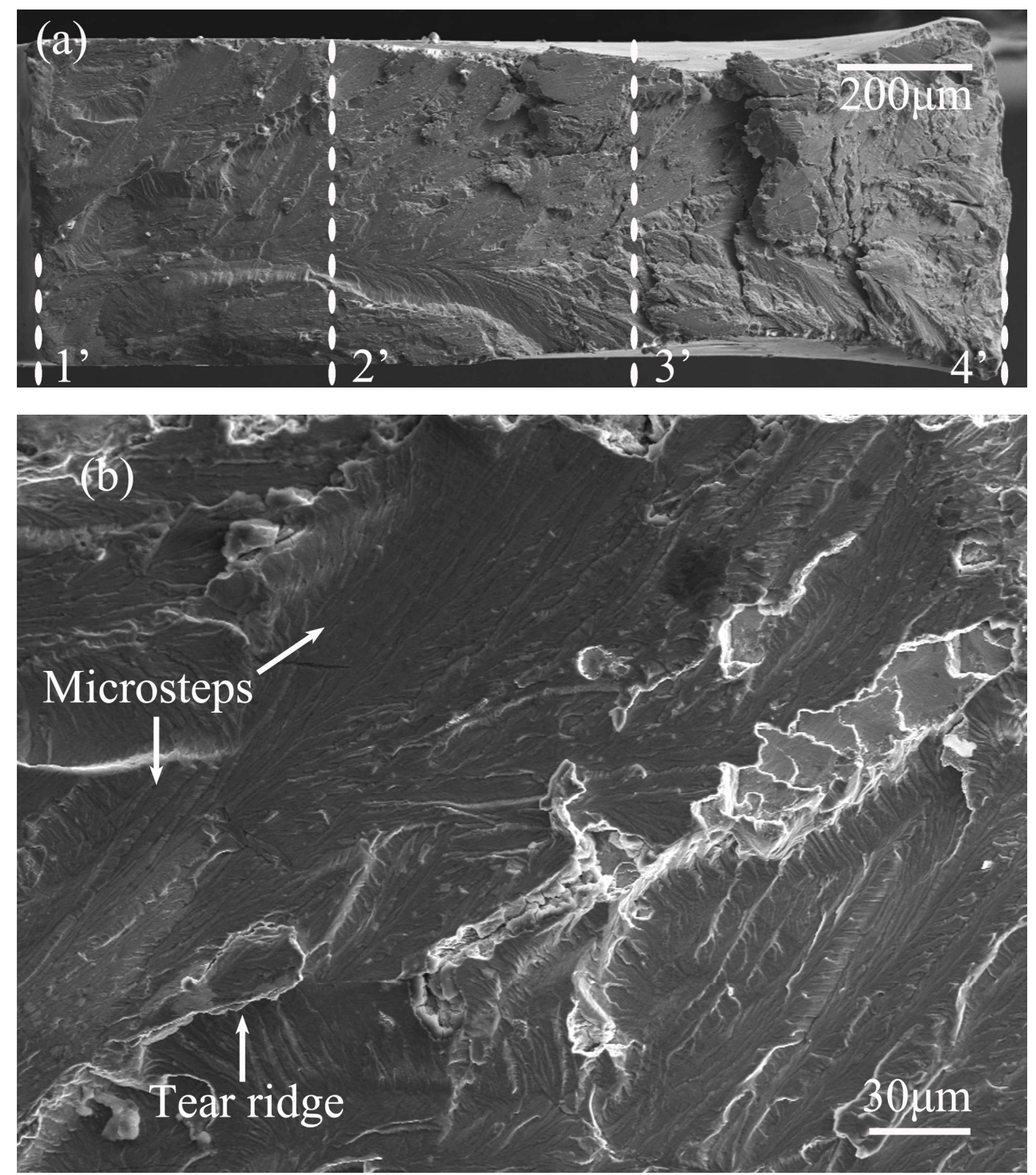

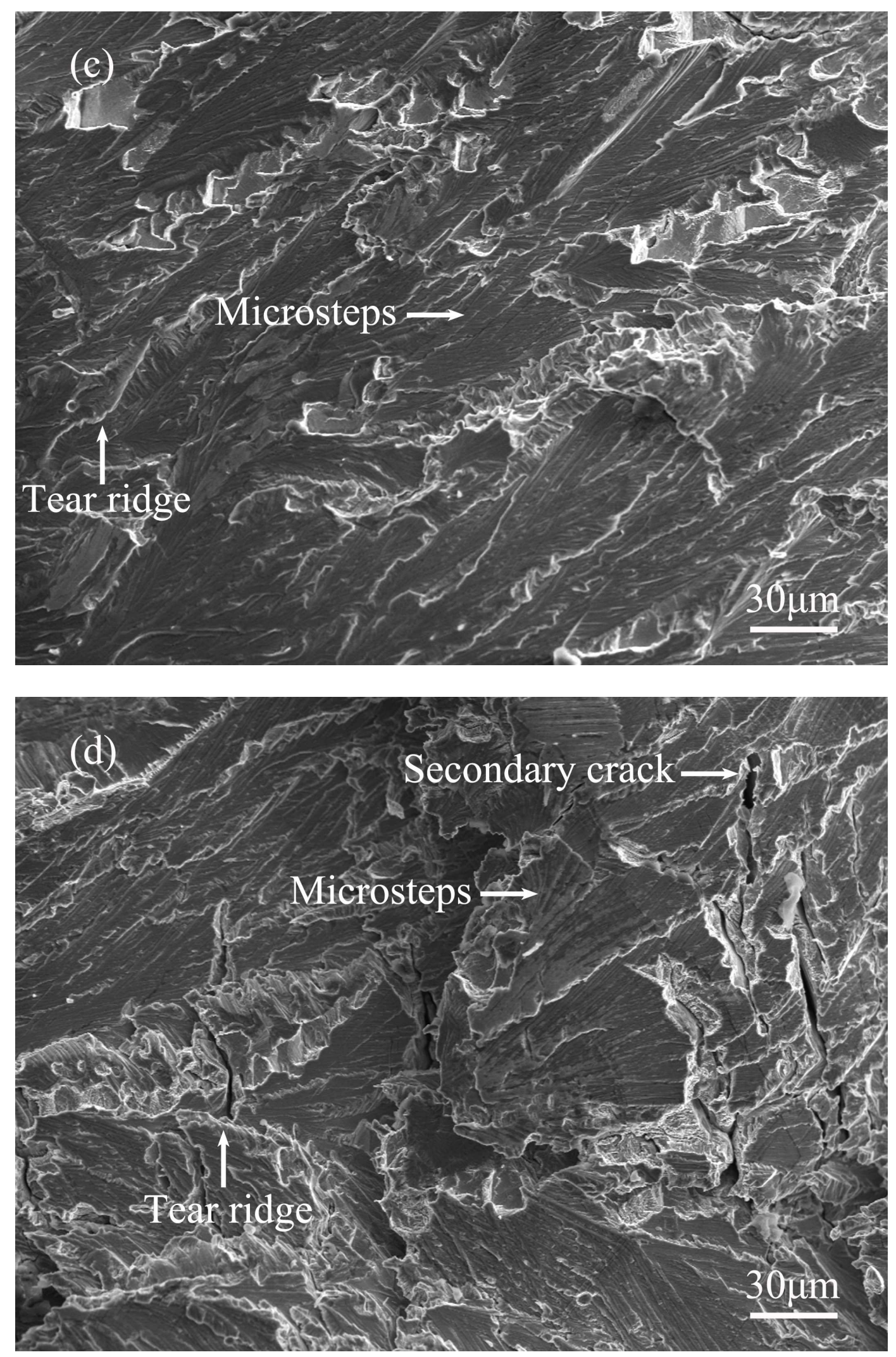
Figure 9

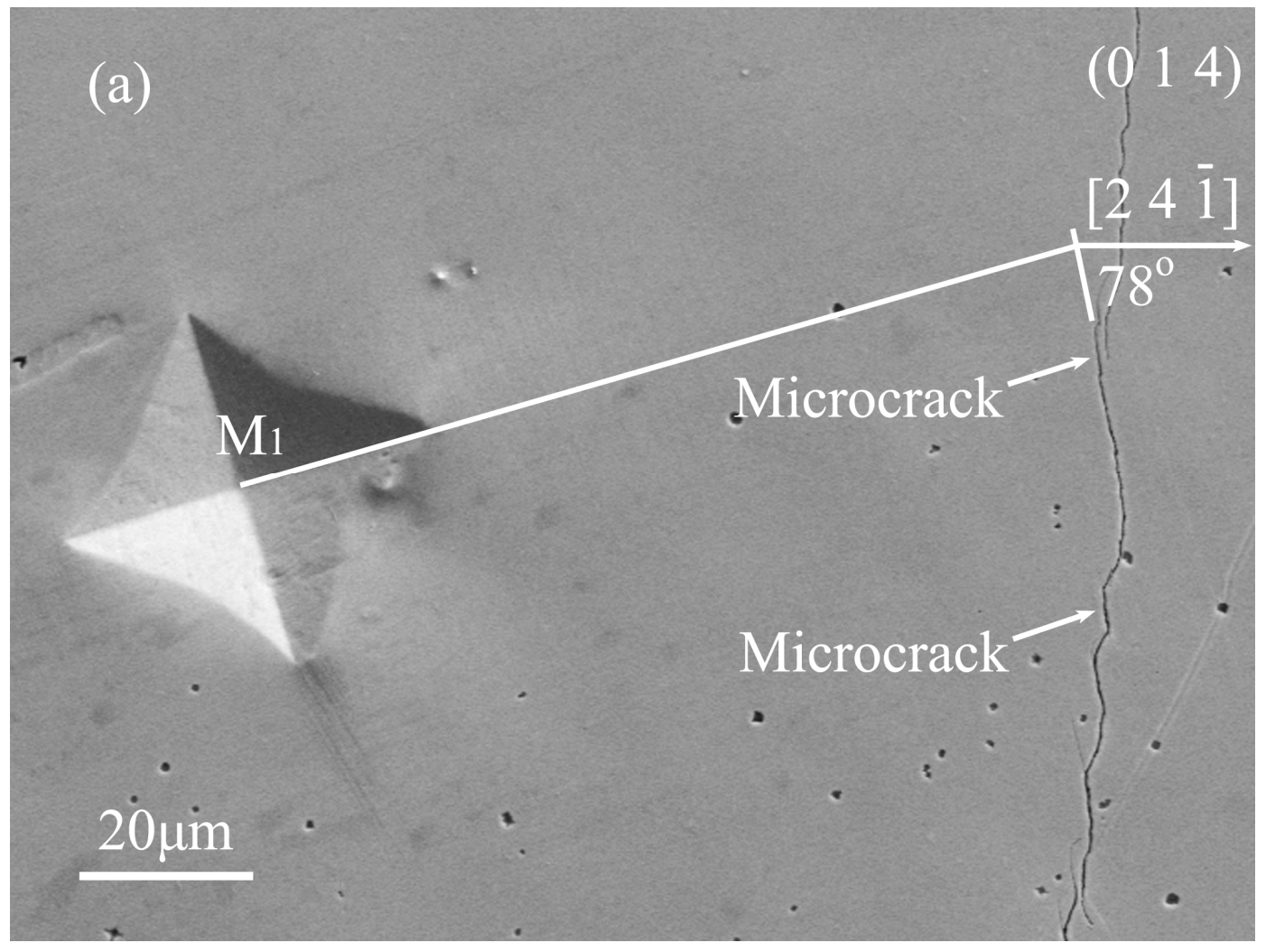

(b)

$x$

$10 \mu \mathrm{m}$

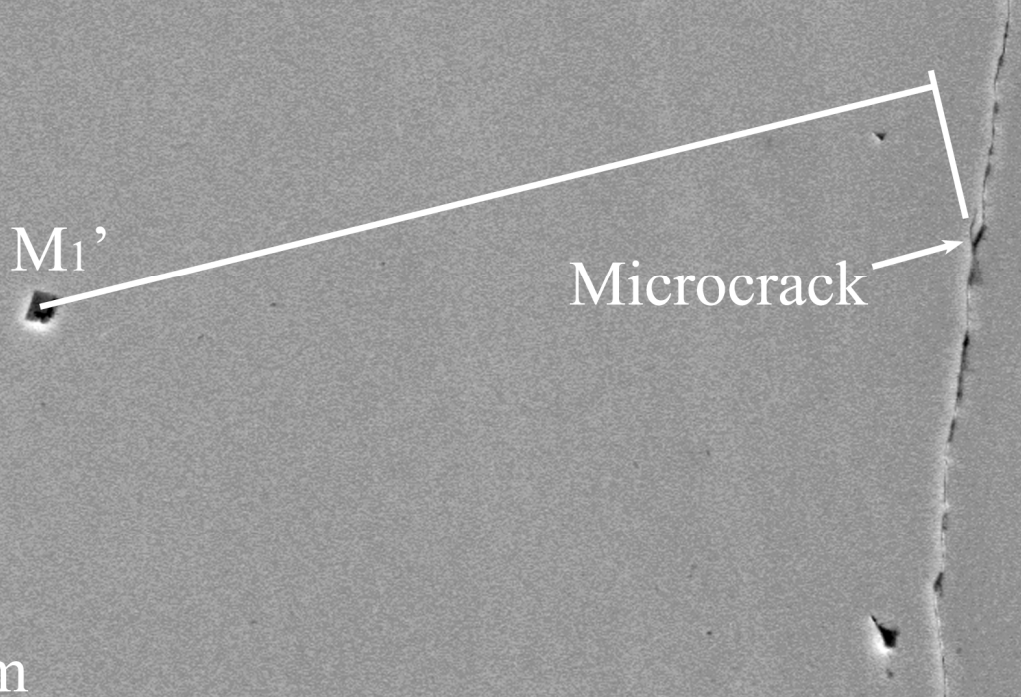


(c)

First surface

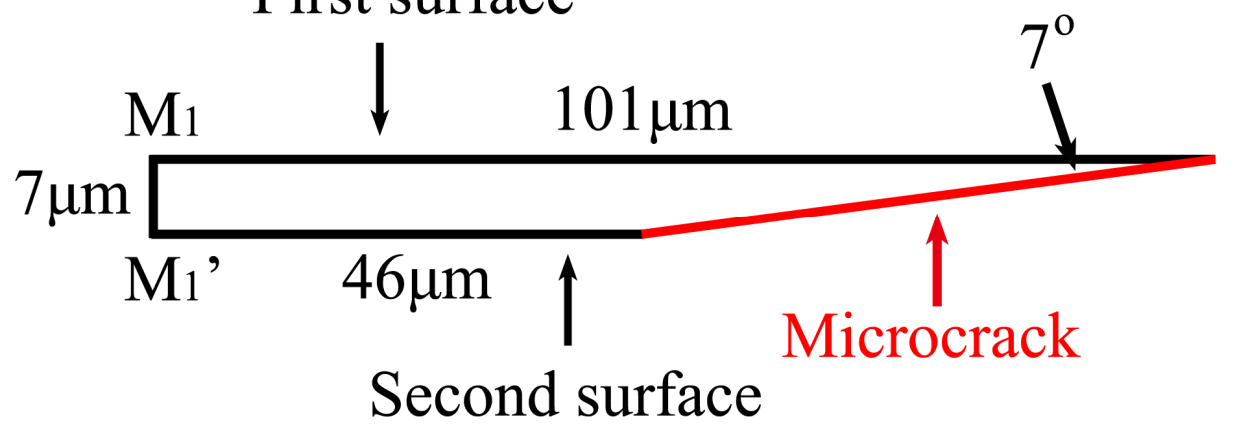


Figure 10
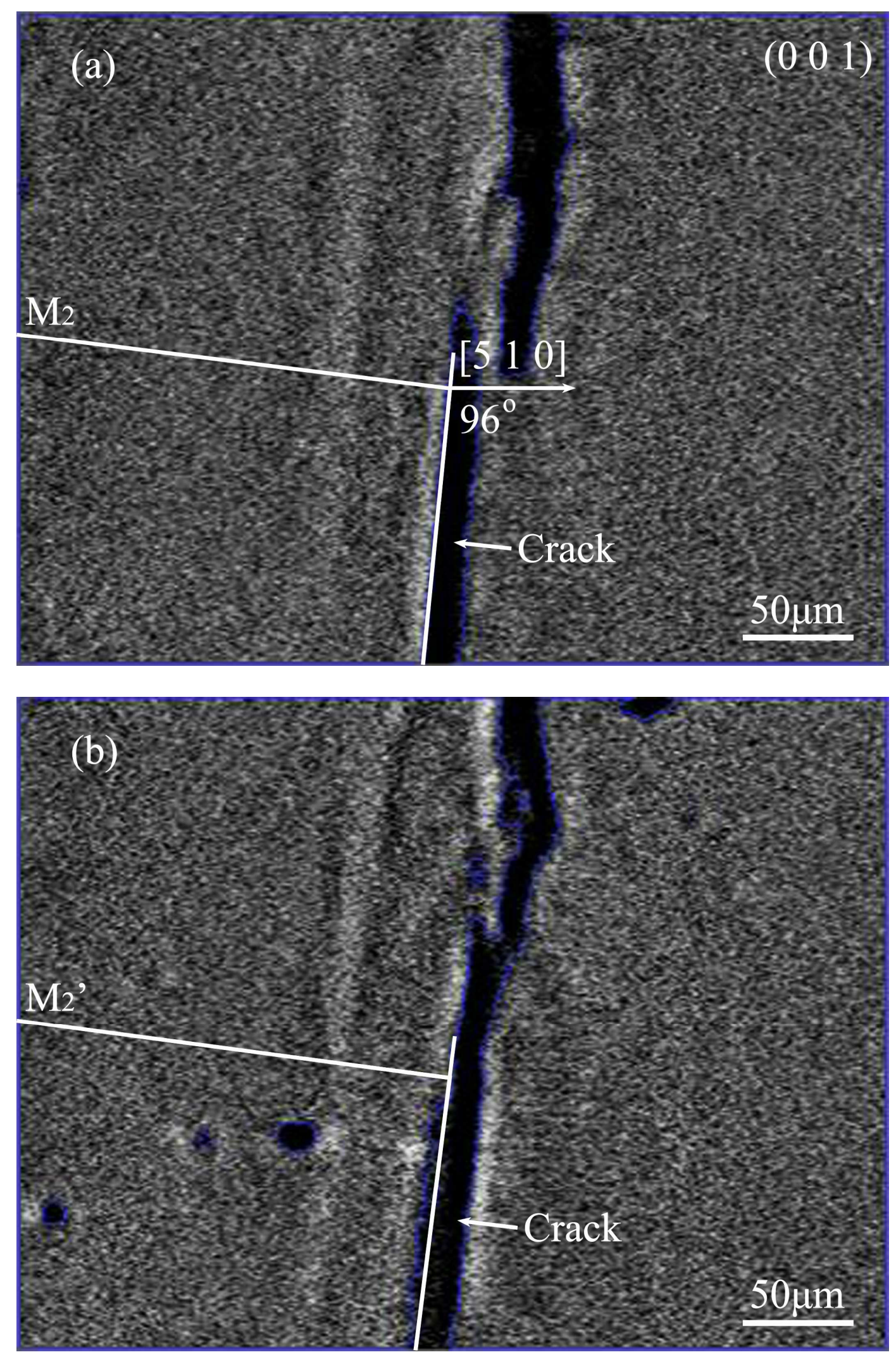
(c)

First surface

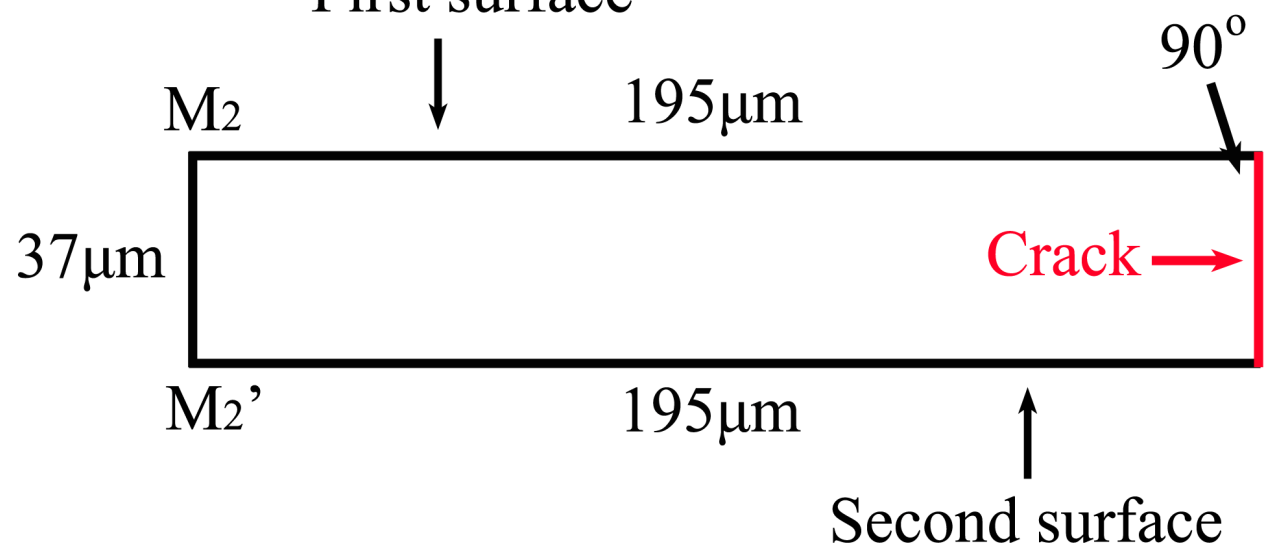


Figure 11

(a)

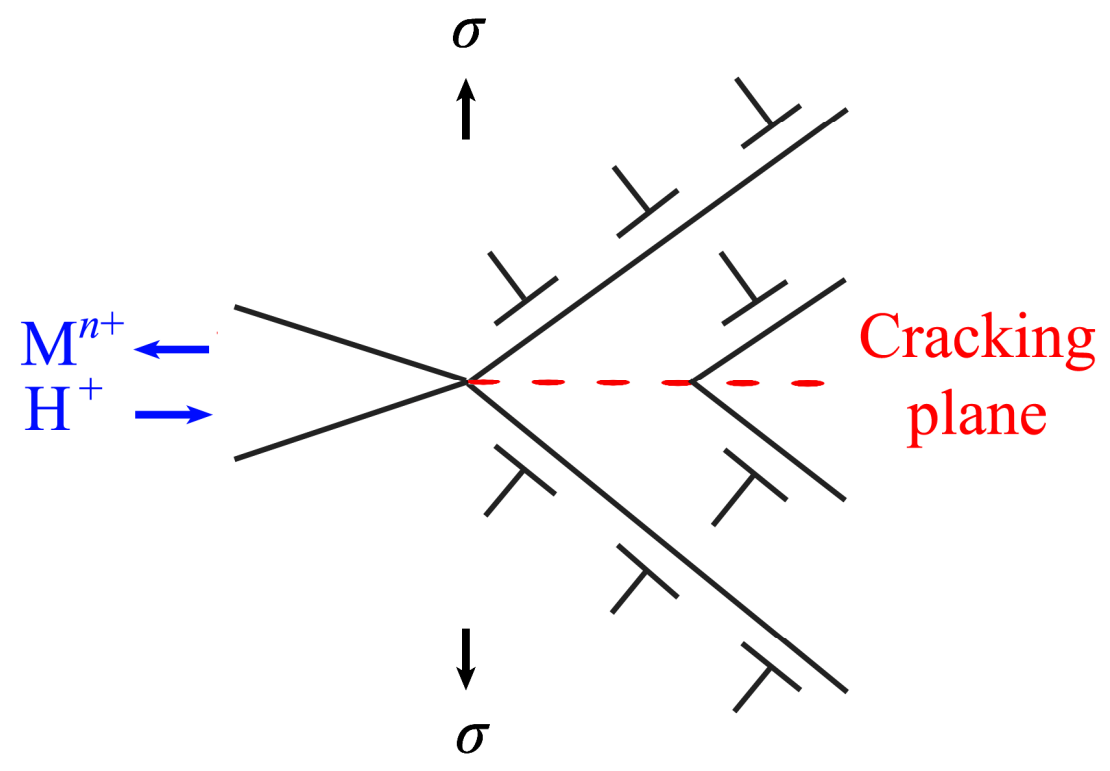

(b)

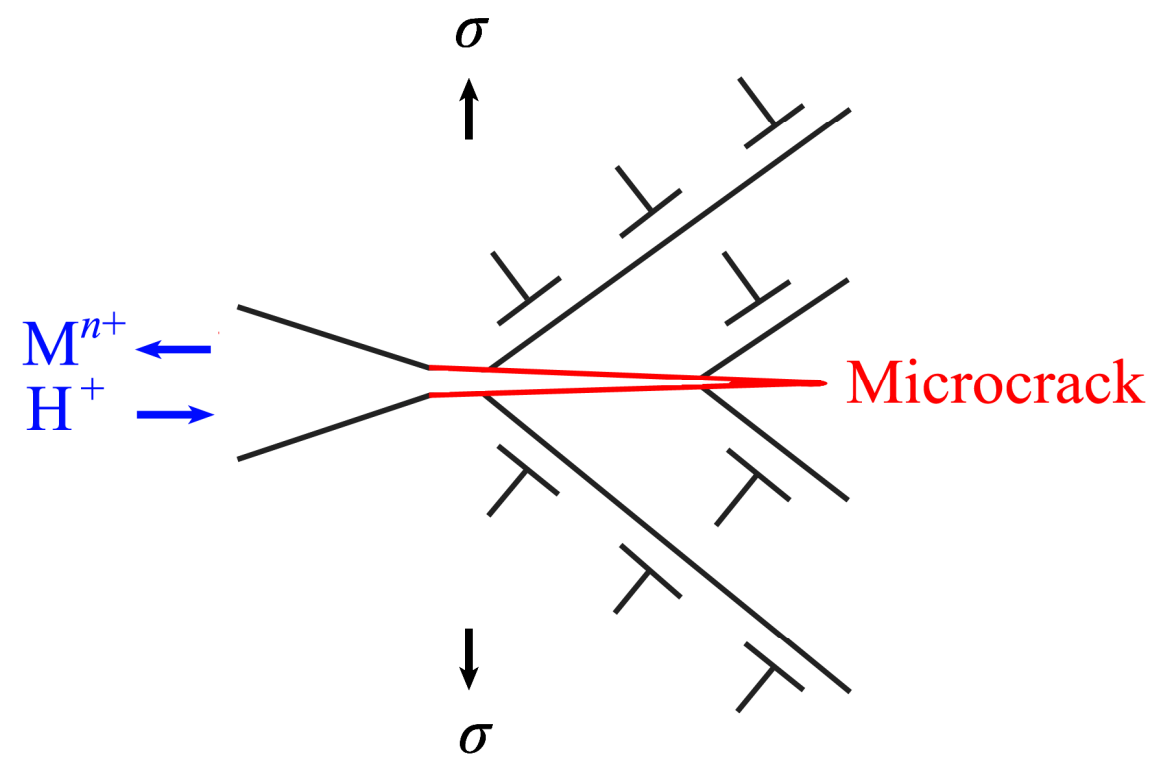


Graphical Abstract

SCC grew along the $\{100\}$ planes without surface slip in 316L single crystals

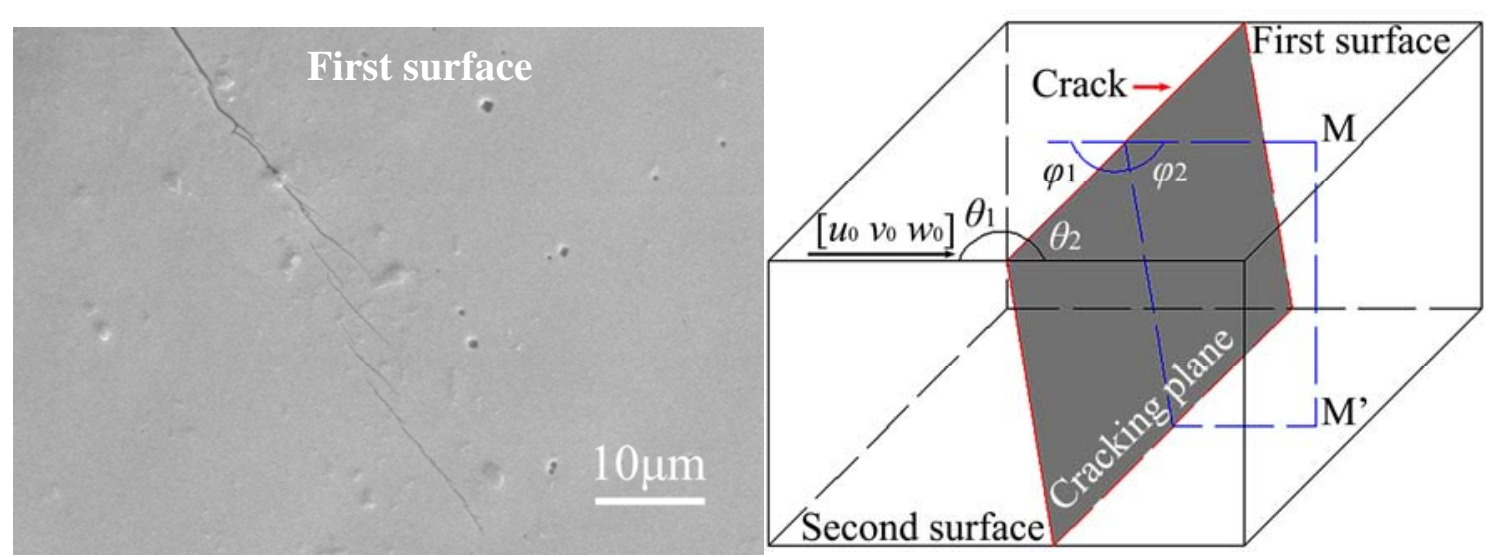

